\title{
Preparedness and Approaches of Healthcare Providers to Tackle the Transmission of Covid-19 among North Shewa Zone Hospitals, Amhara, Ethiopia, 2020.
}

Getaneh Baye Mulu ( $\square$ getanehbaye6@gmail.com )

Debre Berhan University https://orcid.org/0000-0001-8669-6587

worku Misganaw Kebede

Debre Berhan University

Solomon Adanew worku

Debre Berhan University

Yohannes Moges Mittiku

Debre Berhan University

Birhanu Ayelign Jemere

University of Gondar

\section{Research}

Keywords: Coronavirus, Preparedness, Personal protective equipment, Health care provider, North Shewa

Posted Date: June 24th, 2020

DOI: https://doi.org/10.21203/rs.3.rs-36151/v1

License: (c) (1) This work is licensed under a Creative Commons Attribution 4.0 International License.

Read Full License 


\section{Abstract \\ Background}

Coronavirus disease 2019 (COVID-19 is an emerging respiratory disease that is caused by a novel coronavirus and was first detected in December 2019 in Wuhan, China. The disease is highly infectious, and its main clinical symptoms include fever, dry cough, fatigue, myalgia, and dyspnea. Health care providers are in front in fighting the coronavirus spread by making themselves the risk of contracting the disease. This study aimed to assess the preparedness and approaches of healthcare providers to tackle the transmission of COVID-19 among North Shewa Zone Hospitals.

\section{Methods}

Facility-based cross-sectional study was conducted from April to May 2020 among 422 healthcare providers in the North Shewa Zone, Amhara, Ethiopia using a self-administered questionnaire. Study subjects were selected through systematic random sampling based on their proportional distribution of sample size to each hospital. A structured questionnaire will be used to collect data. The data were coded and entered into the Epi data 4.2.1 version and the analysis was carried out in statistical package for social science 25 versions.

\section{Results}

404 participants involved in the study gives a response rate of $95.7 \%$. The self-satisfaction of healthcare providers revealed 301 (74.5\%) of study participants feel unsafe in their workplace. Two-third, 260 $(64.4 \%)$ of them responded that they feel anxious while working with febrile patients. Nearly one -third (31\%), $27.4 \%, 15.9 \%, 14.5 \%, 14.2 \%$ of HCP had access to gloves, facemask, goggle, shoe, and apron respectively in hospitals.

\section{Conclusion}

Protecting healthcare workers is a public health priority. Access to essential personal protective equipment during the COVID-19 pandemic was limited. The poor perception of healthcare professionals about not having enough support from medical institutions and public health authorities raises the need to urgently implement strategies to protect healthcare workers in the time of the COVID-19 pandemic.

\section{Introduction}

In human history in 1918 Spanish flue was the reason for 50 million or more deaths. It has been the benchmark for other pandemics and emerging diseases. Another growing epidemic of novel coronavirus infectious disease (Covid-19), which is caused by severe acute respiratory syndrome coronavirus 2 
(SARS-CoV-2). Coronaviruses comprise a large family of viruses that cause respiratory and intestinal infections in animals and humans, including the Middle East respiratory syndrome (MERS) and SARS. SARS first emerged in the Guangdong province, China, causing the 2002-2003 epidemic. Since midDecember 2019, several cases of a pneumonia-like disease (with symptoms including fever, difficulty in breathing, cough, and invasive lesions on both lungs) of unknown cause have emerged in the central Chinese city of Wuhan $(1,2)$.

During this pandemic period mental health services with other countries affected by the COVID-19 pandemic, in a different population, vulnerable groups of the communities like elderly individuals, survivors of COVID-19 infections as re-infection is high, and frontline health care providers need proper psychological support. And sufficient guidance and counseling are essential, especially in the developing world. With a timely and close collaboration with different nations and institutions, the mental health challenges caused by the COVID-19 pandemic can be adequately addressed (3).

Globally, there have been more than nearly 6 million confirmed cases, and more than 357,000 registered deaths. On March 3, 2020, the first patient with COVID-19 was detected in Addis Ababa, Ethiopia. From then until May 28, 2020, another 831 COVID-19 cases were identified in Ethiopia (4).

Health care providers are in front in fighting the coronavirus spread by making themselves the risk of contracting the disease. Keeping the well-being in the working environment for a health care provider and an effective plan is essential in each phase of a pandemic (5).

As the coronavirus pandemic rises, trained health providers are a key resource to combat the infection. They are the main priority in many countries, but those healthcare providers have many concerns during this period like availability of necessary equipment's in addition to this they have great concerns for their safety as well as their families because they are worried about transmitting the infection to their family members (6).

In Africa, the COVID-19 pandemic is rampantly is rising today, even though, there are key constraints to avert the progression of the pandemic, especially in human resources and shortage of personal protective equipment (PPE). In the area of limited or shortage of protective equipment, the risk of COVID-19 infection and dying will be high among frontline healthcare providers this will be a huge blow for countries and healthcare providers as a whole for all communities. Africa is known with limited resources, weak health system which will be made double burdened. As a result, the government is expected to full fill the necessary equipment and keep the safety of healthcare providers (7).

Personal protective equipment is the main protection for healthcare providers specifically if the virus spreads to the community, as the numbers of patients with unknown contact history. In addition to this Safety of workplace and fulfillment of Standards for protection, furthermore training how to use and remove personal protective equipment is needed to increase preparedness (8). 
Health care providers are in the front line to face COVID-19 outbreak and as a result, they are at greater risk of exposure to bio-hazards that put them at risk of infection with an outbreak pathogen (COVID-19). Hazards include pathogen exposure, long working hours, psychological distress, fatigue, occupational burnout, stigma, and physical and psychological violence (9).

As the world is being hit hard by coronavirus disease 2019 pandemic, health care systems of countries in the world became stunned with a high demand for infectious patients' needs testing and care. Averting coronavirus pandemic infection is on the hands of health care workers (HCWs) and patients rely on the effective use of personal protective equipment (PPE). A serious shortage of all of this equipment is expected to develop or has already developed in areas of high demand. So, An increased demand for PPE relies on continuous and reliable supply as the hospitals are overwhelmed by a rapid increase in ill COVID-19 patients (10).

The findings of this study will help in many aspects such as, better planning for awareness campaigns, guide different health authorities accordingly to modulate their policies as needed and to correct some untoward behaviors to stop the spread of the virus which may result in rapid control and containment of the ongoing pandemic. Therefore, this study aimed to assess the preparedness and approaches in tackling the transmission of COVID-19 among health care workers at North Shewa zone hospitals.

\section{Methods}

\section{Study design, setting, Area and Population}

The institution-based cross-sectional study design was conducted in North Shewa zone hospitals, Amhara Regional State from April to May 2020. North Shewa is one of the zones in the Amhara regional state. North Shewa has 11 primary Hospitals (of which the two are private Hospitals) and one comprehensive specialized hospital. According to zonal health Department data, more than 2000 health care worker provider serves around 3 million people in North Shoa Zone.

All healthcare providers who were working in hospitals at the North Shewa zone were source population whereas, all healthcare providers who are working in selected hospitals of North Shewa Zone during the study period were the study population. Selected healthcare providers who in selected hospitals working in the hospital of North Shewa Zone were study units.

\section{Eligibility criteria}

Inclusion criteria: All health professionals who are working in the selected hospitals whereas HCP who are seriously ill and annual leave were excluded.

\section{Sample size determination}

The sample size were calculated using a single population proportion formula with assumption of $95 \%$ confidence level, marginal of error $5 \%$, and $50 \%$ 
$\mathrm{n}=\mathrm{Z}(\mathrm{a} / 2)^{2} \mathrm{p}(1-\mathrm{p}) / \mathrm{d}^{2}$

Where $\mathrm{n}=$ minimum sample size:

Z (a / 2)2 = 95\% Confidence level:

$\mathrm{P}=$ proportion of health care provider preparedness in tackling transmission of COVID-19 $\mathrm{P}=50 \%$ since there is no previous study

$D=5 \%$ margin of error

In which $\mathrm{n}=\left[(1.96)^{2}(0.5)(1-0.5)\right] /(0.05)^{2}$

$=384$ adding $10 \%$ non-response rate; $n=422$

\section{Sampling technique and procedure}

North Shewa Zone has 12 Hospitals, among these 5 Hospitals were selected by lottery methods. Then, the possible number of respondents in each of the Hospitals of the study area were allocated proportionally based on the number of Health workers. Study participants who fulfill the inclusion criteria were selected by systematic random sampling every two intervals using the list of the workers from each hospital by using the monthly payroll as a sampling frame. The total number of the healthcare worker in the selected Hospitals was 860.

\section{Data collection tools and procedures}

The data were collected through a self-administered questionnaire and observation for the practice of standard precaution in fighting against COVID-19 pandemic using checklists. The questionnaire was distributed to the participants by the principal investigators responsible for data collection. The principal investigators also responsible for the respondents with explanations when requested by the respondents. The data collection tool was designed from risk communication \& community Engagement action plan guidance of WHO COVID-19 preparedness \& response and related literature $(11,12)$. Participants from all healthcare professions were selected for the study. The questionnaire was divided into 2 parts. The first part comprised of demographic information of the respondents. The second part assessed the preparedness of healthcare care providers with 26 items of question. Their response was evaluated with four domains: strongly agree, agree, disagree, strongly disagree response. The 3rd part determined the personal protective equipment availability towards COVID-19 with 5 items of the question with a yes-no response.

\section{Data Quality Assurance}

The data collection tool was pretested three days before the actual data collection on $5 \%$ of the calculated sample size of 21 health care providers on Debre Sina primary hospital and necessary adjustment was made. The collected data were checked for completeness, accuracy consistency, and 
clarity. Codes were given to the questionnaire and participant during data collection so that any identified errors were get traced back using the codes.

\section{Data analysis}

Data was entered using Epi-Data version 4.2.1 and analyzed using SPSS 25 statistical software. The descriptive analysis runs first with proportion and summary statistics to describe the study population concerning relevant variables by considering statistical assumptions. Socio-demographic profiles of variables frequency distribution, summary measures such as mean and standard deviation was calculated for outcome variables. When frequencies become smaller than expected, variables were recategorized or merge of the levels was done.

\section{Result}

\section{Result}

From a total of 422 samples, 404 healthcare workers completed the questionnaire with a response rate of $95.7 \%$. Of them, Nurses $166(41.1 \%)$, physicians $77(19.1 \%)$, midwives $60(14.9 \%)$, laboratory technicians $39(9.7 \%)$, pharmacists $29(7.2 \%)$, and other professionals $33(8.2 \%)$. Nearly half of the $207(51.2 \%)$ were in the age group between 25-29 years with a mean age of $29.1 \pm 5.2$ years and more likely to be males (63.1\%). Above half of them had work experience of fewer than five years (64.1\%). Nearly half of them were single 213(52.7) and more likely to be orthodox 360(89.1\%). The above two-thirds was a first degree in level of education (Table 1 ). 
Table 1

shows socio-demographic characteristics of study participants among healthcare providers in the North Shewa Zone Hospitals, Amhara, Ethiopia, $2020(n=404)$.

\begin{tabular}{|c|c|c|c|}
\hline \multicolumn{2}{|l|}{ Character } & \multirow{2}{*}{$\begin{array}{l}\text { Freq. } \\
50\end{array}$} & \multirow{2}{*}{$\begin{array}{l}\text { Percent } \\
12.4\end{array}$} \\
\hline Age & $20-24$ & & \\
\hline & $25-29$ & 207 & 51.2 \\
\hline & $30-34$ & 99 & 24.5 \\
\hline & $>34$ & 48 & 11.9 \\
\hline \multirow[t]{2}{*}{ Sex } & Male & 255 & 63.1 \\
\hline & Female & 149 & 36.9 \\
\hline \multirow[t]{2}{*}{ Work experience } & $\leq 5$ & 259 & 64.1 \\
\hline & $>5$ & 145 & 35.9 \\
\hline \multirow[t]{3}{*}{ Level of education } & Diploma & 98 & 24.3 \\
\hline & Degree & 285 & 70.5 \\
\hline & Masters and Specialist & 21 & 5.2 \\
\hline \multirow[t]{3}{*}{ Marital status } & Married & 187 & 46.3 \\
\hline & Single & 213 & 52.7 \\
\hline & Others* & 4 & 1 \\
\hline \multirow[t]{3}{*}{ Religion } & Orthodox & 360 & 89.1 \\
\hline & Muslim & 26 & 6.4 \\
\hline & Others & 18 & 4.4 \\
\hline \multirow[t]{6}{*}{ Profession } & Physician's & 77 & 19.1 \\
\hline & Nurses & 166 & 41.1 \\
\hline & Midwives & 60 & 14.9 \\
\hline & Pharmacy & 29 & 7.2 \\
\hline & Laboratory & 39 & 9.7 \\
\hline & Others** & 33 & 8.2 \\
\hline \multicolumn{4}{|c|}{ Others ${ }^{\star}=$ widowed and separated } \\
\hline $\mathrm{Ot}$ & nesthesic & rse. & \\
\hline
\end{tabular}




\section{Preparedness of HCP}

Assessment of self-satisfaction of healthcare providers revealed that nearly three fourth $301(74.5 \%)$ of study participants feel unsafe working in their working place. Two-third of 260(64.4\%) of them responded that they feel anxious while working with febrile patients (Table 2). 
Table 2

Preparedness of HCP in tackling COVID-19 in the North Shewa Zone hospitals, Amhara Ethiopia, 2020 (n $=404$ ).

\begin{tabular}{|c|c|c|c|}
\hline Variable & & $\mathbf{N}$ & $\%$ \\
\hline \multirow[t]{2}{*}{ I feel unsafe in working at my workplace } & Agree & 301 & 74.5 \\
\hline & Disagree & 103 & 25.5 \\
\hline \multirow[t]{2}{*}{ I feel anxious while working with febrile patients } & Agree & 260 & 64.4 \\
\hline & Disagree & 144 & 35.6 \\
\hline \multirow[t]{2}{*}{ I feel at risk to contract COVID-19 infection at work } & Agree & 345 & 85.4 \\
\hline & Disagree & 59 & 14.6 \\
\hline \multirow[t]{2}{*}{ I feel obliged to care for COVID-19 infected patients } & Agree & 289 & 71.5 \\
\hline & Disagree & 115 & 28.5 \\
\hline \multirow[t]{2}{*}{ I felt hopeless I might eventually get COVID-19 at work } & Agree & 191 & 47.3 \\
\hline & Disagree & 213 & 52.7 \\
\hline \multirow[t]{2}{*}{ I feel threatened if one of my colleagues contracted COVID-19 } & Agree & 262 & 64.9 \\
\hline & Disagree & 142 & 35.1 \\
\hline \multirow[t]{2}{*}{ If I get COVID-19, I do not feel confident employees care for me } & Agree & 187 & 46.3 \\
\hline & Disagree & 217 & 53.7 \\
\hline \multirow[t]{2}{*}{ I feel that I should limit my social activities due to COVID-19 } & Agree & 339 & 83.9 \\
\hline & Disagree & 65 & 16.1 \\
\hline \multirow[t]{2}{*}{ I feel I will transmit COVID-19 to my family members } & Agree & 319 & 79.0 \\
\hline & Disagree & 85 & 21.0 \\
\hline \multirow[t]{2}{*}{ I feel that my family will avoid me since I work in a hospital } & Agree & 179 & 44.3 \\
\hline & Disagree & 225 & 55.7 \\
\hline \multirow[t]{2}{*}{ I feel I should avoid leaving my home due to COVID-19 } & Agree & 177 & 43.8 \\
\hline & Disagree & 227 & 56.2 \\
\hline \multirow[t]{2}{*}{ I feel my family will not look after me if I will be infected } & Agree & 177 & 43.8 \\
\hline & Disagree & 227 & 56.2 \\
\hline \multirow[t]{2}{*}{ I don't feel confident in telling my family and friends if I am infected. } & Agree & 161 & 39.9 \\
\hline & Disagree & 243 & 60.1 \\
\hline
\end{tabular}




\begin{tabular}{|c|c|c|c|}
\hline Variable & & $\mathbf{N}$ & $\%$ \\
\hline \multirow[t]{2}{*}{ I feel that my institution didn't support me the COVID-19 crisis } & Agree & 228 & 56.4 \\
\hline & Disagree & 176 & 43.6 \\
\hline \multirow[t]{2}{*}{ li feel my institution losing control of the COVID-19crisis } & Agree & 240 & 59.4 \\
\hline & Disagree & 164 & 40.6 \\
\hline \multirow[t]{2}{*}{ I feel overwhelmed with the new COVID-19 regulations } & Agree & 260 & 64.4 \\
\hline & Disagree & 144 & 35.6 \\
\hline \multirow[t]{2}{*}{ I feel COVID-19 crisis increased my workload } & Agree & 274 & 67.8 \\
\hline & Disagree & 130 & 32.2 \\
\hline \multirow[t]{2}{*}{ I feel that the increased workload nor met with proper staffing } & Agree & 238 & 58.9 \\
\hline & Disagree & 166 & 41.1 \\
\hline \multirow[t]{2}{*}{ I feel absence from work reduce the chance of getting COVID-19 } & Agree & 218 & 54.0 \\
\hline & Disagree & 186 & 46.0 \\
\hline \multirow[t]{2}{*}{ In case I have COVID-19, I feel ashamed of telling my manager/colleagues } & Agree & 141 & 34.9 \\
\hline & Disagree & 263 & 65.1 \\
\hline \multirow[t]{2}{*}{ I feel I should change my current job due to COVID-19 crisis } & Agree & 142 & 35.1 \\
\hline & Disagree & 262 & 64.9 \\
\hline \multirow[t]{2}{*}{ I am not confident with the current infection control measures } & Agree & 248 & 61.4 \\
\hline & Disagree & 156 & 38.6 \\
\hline \multirow[t]{2}{*}{ I do not feel proper infection control training has been offered to me } & Agree & 246 & 60.9 \\
\hline & Disagree & 158 & 39.1 \\
\hline \multirow{2}{*}{$\begin{array}{l}\text { I do not feel an infection specialist is accessible to respond to my } \\
\text { concerns }\end{array}$} & Agree & 248 & 61.4 \\
\hline & Disagree & 156 & 38.6 \\
\hline \multirow[t]{2}{*}{ I do not feel there is COVID-19 outbreak plan set at my area } & Agree & 217 & 53.7 \\
\hline & Disagree & 187 & 46.3 \\
\hline \multirow[t]{2}{*}{ I don't feel safe at work when I use the standard precautions } & Agree & 219 & 54.2 \\
\hline & Disagree & 185 & 45.8 \\
\hline
\end{tabular}

\section{Personal protective equipment}


Nearly one -third $111(31 \%)$ Gloves, $98(27.4 \%)$, facemasks 57(15.9\%) goggles, 51(14.2\%) gowns/ apron and $41(11.5 \%)$ shoe PPE were available in hospitals. Below, the graph shows the type of personal protective equipment and its varieties (Fig. 1).

\section{Discussion}

This study assessed preparedness and approaches of the health care provider in tackling COVID-19 among health care providers working in hospitals of the North Shewa zone. Nowadays, humankind in the world is facing devastating COVID pandemic which needs all institutions, communities, organizations both governmental and non-governmental organizations need to collaborate to avert the progression of the diseases. As a result, research to find a new way to combat it, and we are urged to conduct research.

\section{Preparedness and Emotions of healthcare providers}

During a catastrophic global pandemic such as the COVID-19, it is common for every person to experience intense suffering from anxiety depression, predominantly as a result of social isolation. Physicians, nurses, and other frontline health care professionals are particularly exposed to negative mental health effects during caring for patients. The ongoing COVID-19 pandemic is also taking a massive toll on the mental and emotional well-being of front-line health care workers around the world. Healthcare providers will suffer longer duration shifts, work-life balance disturbances and worries about taking the disease relatives will be led to intense stress and anxiety, physical and mental fatigue, and burnout for this group of individuals. Besides, healthcare providers concerned about their well-being and their families and friends. As a result of the COVID-19 pandemic, many health care providers are facing physical separation and increased in care demands, equipment shortages, and the higher risk of COVID19 infection. These factors can all lead to decreased mental stability and will increase the chance of stress and anxiety.

Preparedness of health care provider assessed by 26 -items of question. The self-satisfaction of healthcare providers revealed that nearly three fourth $301(74.5 \%)$ of study participants feel unsafe working in their working place. Two-third of 260(64.4\%) of them responded that they feel anxious while working with febrile patients. nearly half $191(47.3 \%)$ of the HCP agreed that they are feeling hopeless they might eventually get COVID-19 at work. Two-third of HCP 262 (64.9\%) agreed that they feel threatened if one of their colleagues contracted COVID-19.

The majority of the HCP 339 (83.9\%) responded that they feel that they should limit their social activities due to COVID-19. Above three-fourth of HCP 319 (79\%) agreed that they feel they will transmit COVID-19 to their family members. Below half of the 179(44.3\%) feel that their families will avoid them since they are working in hospitals. Above half 227 (56.2\%) of the HCP feels that their family will not look after them if they will be infected with COVID-19 and 177(43.8\%) agreed that if they are infected with COVID-19 their family will not look after them. Nearly two-thirds of 243(60.1\%) of the respondents didn't feel confident in telling their family and friends if they are infected with COVID-19. From the total participants, 339 (83.9\%) 
and $240(59.4 \%)$ of HCP feel that their institution didn't support them and loses control in the COVID-19 crisis respectively.

For HCP in North Shoe Zone, safety from infection was the main concern. From this study $196(76.9 \%)$ males, and $105(70.5 \%)$ females feel unsafe in working place. In profession, majority of HCP: midwife 50(83.3\%), 64(83.1\%) physician, 121(72.9\%) Nurses, 26 (66.7\%) Laboratory, 11(61.1\%) pharmacy, and 29 (87.8\%) reported they feel unsafe in working place.

\section{Availability of personal protective equipment}

As the coronavirus disease 2019 (COVID-19) pandemic risen, the world healthcare systems have become stunned with a potential shortage of personal protective equipment (PPE). Averting spread of infection to and from health care providers and patients depends on the effective use of PPE: gloves, facemasks, goggles, face shields, respirators, and gowns. A serious scarcity of these is expected to develop or has already developed in places of high demand. PPE, previously universal and throw away in the hospital environment, is now a scarce and expensive resource in several regions when it is important the most care for highly infectious patients like COVID-19. In this facility-based cross-sectional study the availability of personal protective equipment in north Shewa zone hospitals was 119 (29.5\%) This finding is consistent with a study done in the USA (13). Gloves $111(31 \%)$, facemasks $98(27.4 \%)$, goggles 57(15.9\%), gowns/ apron 51(14.2\%), and shoe 41(11.5\%) PPE were available. The availability of PPE in north Shewa zone hospitals was much lower than a study conducted in Latin America which revealed that gloves (91.1\%), gowns (67.3\%), face masks (83.9\%), and N95 masks (56.1\%)(14). This might be due study time which was done early that health care providers could be conscious to use PPE and socioeconomic difference.

\section{Strength}

Data were collected by a trained BSc nurse. The study tried to address all types of health care providers.

\section{Limitations}

It was limited by a lack of published literature. Participants were asked to answer the preparedness of healthcare professionals. Recruitment of participants was based on their willingness to participate and access to social networking websites and applications; therefore, the study population does not encompass participants without those resources. Most of the responders may work in the hospitals of the different fields where the exposure to critical COVID-19 patients may be limited; therefore, their reality and perspective about COVID-19 could differ.

\section{Conclusions}

Protecting healthcare workers is a public health priority. In this study of healthcare providers working in North Shewa zone hospitals. We are reported limited access to essential personal protective equipment during the COVID-19 pandemic. The poor perception of healthcare professionals about not having 
enough support from medical institutions and public health authorities raises the need to urgently implement strategies to protect healthcare workers in the time of the COVID-19 pandemic.

As the pandemic continues, important clinical and policy strategies are needed to support health care workers. The study identified a vulnerable group susceptible to psychological distress. Educational interventions should target health care workers to ensure the understanding and use of infectious control measures. Psychological support could include counselling services and the development of support systems among colleagues.

\section{Abbreviations}

HCP: Health Care Provider

PPE: personal protective equipment

DB: Debre Berhan

COVID-19: Corona Virus Infectious Disease 19

\section{Declarations}

\section{Ethical approval}

Ethical clearance was obtained from the Debre Berhan University Research Ethics and Publication Committee before conducting the study. Further permission was obtained from each hospital administration. Any information related to personal identification of the study participants was not recorded to maintain the confidentiality of the study. Written consent was obtained from all health care providers.

\section{Consent for publication}

Not applicable

\section{Availability of data and material}

Data support these findings are contained within the manuscript and will share upon request to the corresponding author.

\section{Competing interests}

The authors declare that they have no competing interests.

\section{Funding}


The study was funded by Debre Berhan University, Ethiopia. The funder had no role in the study design, data collection, and analysis, interpretation of data, the decision to publish, or preparation of the manuscript.

\section{Authors' contributions}

All authors contributed to data analysis, drafting or revising the article, gave final approval of the version to be published and agreed to be accountable for all aspects of the work.

\section{Acknowledgment}

First, we would like to express our deepest gratitude and appreciation to North Shoa Zone Hospitals for permitting us to conduct this research. We would also like to extend our appreciation to the data collectors and participants.

\section{References}

1. Du Toit A. Outbreak of a novel coronavirus. Nature Reviews Microbiology. 2020;18(3):123-.

2. Morens DM, Daszak P, Taubenberger JK. Escaping Pandora's box-another novel coronavirus. New England Journal of Medicine. 2020;382(14):1293-5.

3. Xiang Y-T, Jin Y, Cheung T. Joint International Collaboration to Combat Mental Health Challenges During the Coronavirus Disease 2019 Pandemic. JAMA Psychiatry. 2020.

4. www.worldometers.info/coronavirus.

5. Nagesh S, Chakraborty S. Saving the frontline health workforce amidst the COVID-19 crisis: Challenges and recommendations. J Glob Health. 2020;10(1):010345-.

6. The L. COVID-19: protecting health-care workers. Lancet (London, England). 2020;395(10228):922-.

7. Chersich MF, Gray G, Fairlie L, Eichbaum Q, Mayhew S, Allwood B, et al. COVID-19 in Africa: care and protection for frontline healthcare workers. Globalization and Health. 2020;16(1):46.

8. Wong J, Goh QY, Tan Z, Lie SA, Tay YC, Ng SY, et al. Preparing for a COVID-19 pandemic: a review of operating room outbreak response measures in a large tertiary hospital in Singapore. Canadian Journal of Anesthesia/Journal canadien d'anesthésie. 2020:1-14.

9. Abbasi J. Prioritizing Physician Mental Health as COVID-19 Marches On. JAMA.

10. Livingston E, Desai A, Berkwits M. Sourcing Personal Protective Equipment During the COVID-19 Pandemic. JAMA. 2020;323(19):1912-4.

11. Organization WH. COVID-19: operational guidance for maintaining essential health services during an outbreak: interim guidance, 25 March 2020. World Health Organization; 2020.

12. Zhong B-L, Luo W, Li H-M, Zhang Q-Q, Liu X-G, Li W-T, et al. Knowledge, attitudes, and practices towards COVID-19 among Chinese residents during the rapid rise period of the COVID-19 outbreak: a quick online cross-sectional survey. International Journal of Biological Sciences. 2020;16(10):1745. 
13. Mason DJ, Friese CR, editors. Protecting health care workers against COVID-19-and being prepared for future pandemics. JAMA Health Forum; 2020: American Medical Association.

14. Delgado D, Wyss Quintana F, Perez G, Sosa Liprandi A, Ponte-Negretti C, Mendoza I, et al. Personal Safety during the COVID-19 Pandemic: Realities and Perspectives of Healthcare Workers in Latin America. International Journal of Environmental Research and Public Health. 2020;17(8):2798.

\section{Figures}

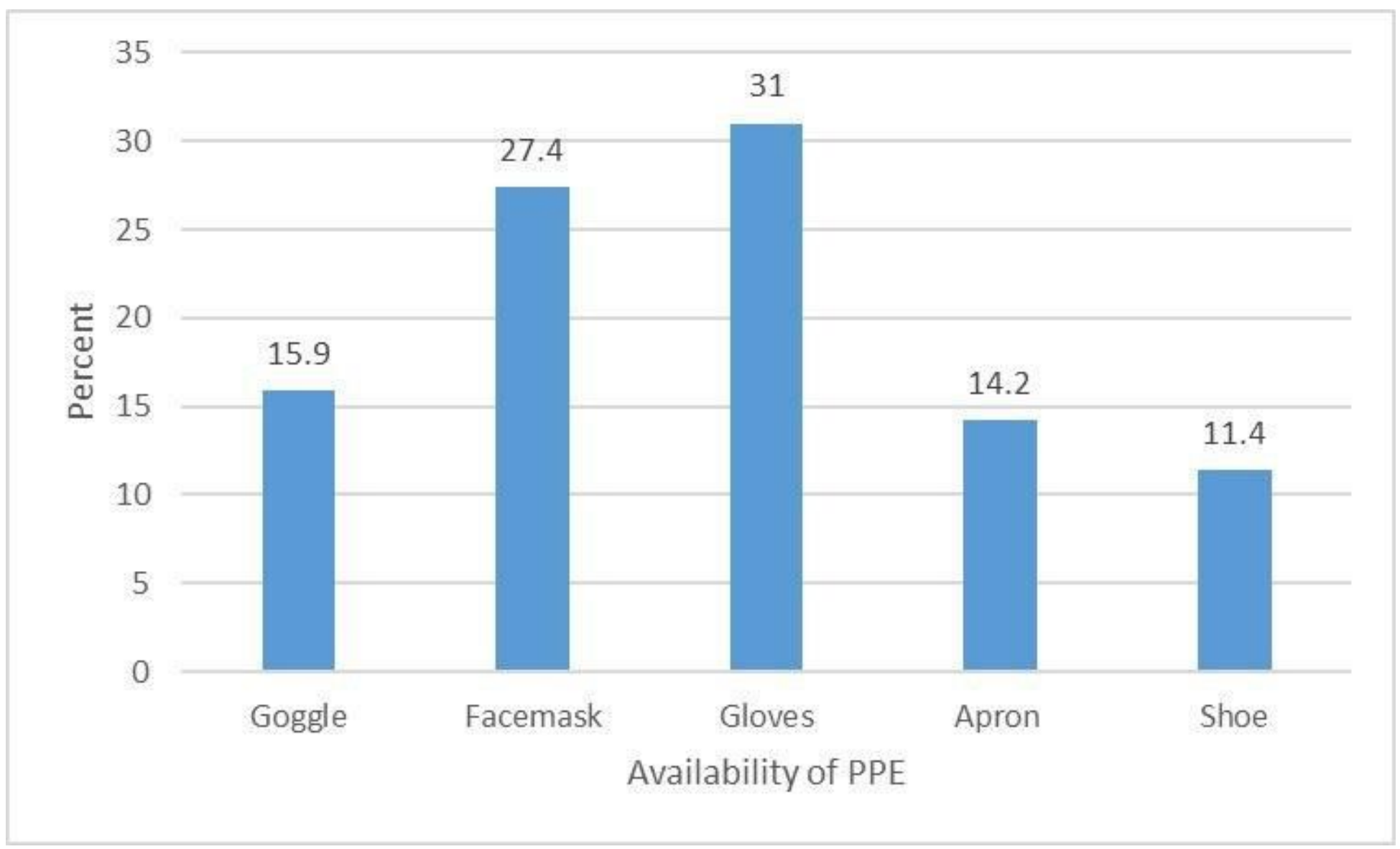

\section{Figure 1}

showing availability of personal protective equipment's in hospitals of North Shewa zone Amhara, Ethiopia 2020.

\section{Supplementary Files}

This is a list of supplementary files associated with this preprint. Click to download.

- CoverLetterforBMCvirology.docx 